\title{
Detection of Dried Saliva on Human Skin using an Ultra Violet Spectrometer: A Technical Report
}

\author{
Shilpa Dutta Malik", Upender Malik², Aparna K. Sanath ${ }^{1}$, Manish Goyal' ${ }^{3}$, \\ Meghanand T. Nayak ${ }^{1}$ and Aman Chowdhry ${ }^{4}$ \\ 'Department of Oral Pathology and Microbiology, Teerthanker Mahaveer Dental College and Research Centre, \\ Moradabad - 244 001, Uttar Pradesh, India; jbnjmd@gmail.com \\ ${ }^{2}$ Department of Oral Medicine and Radiology, Teerthanker Mahaveer Dental College and Research Centre, \\ Moradabad - 244 001, Uttar Pradesh, India \\ ${ }^{3}$ Department of Orthodontics and Dentofacial Orthopedics and Microbiology, Teerthanker Mahaveer \\ Dental College and Research Centre, Moradabad - 244 001, Uttar Pradesh, India \\ ${ }^{4}$ Department of Oral Pathology and Microbiology, Jamia Millia Islamia Dental College, New Delhi, India
}

\begin{abstract}
Introduction: Human beings produce saliva, which is a vital secreted fluid. A significant quantity of saliva is left on the skin while biting, sucking, or licking. This saliva if effectively detected could be utilized as forensic evidence. DNA extraction and typing is complex and expensive technique; hence, ultraviolet (UV) spectroscopy could be used as an effective tool in detecting saliva. Aim: The aim was to detect the presence of dried saliva on the human skin using a UV spectrometer. Materials and Methodology: In this study, 50 volunteers deposited their saliva on their own arm. The saliva was air-dried, then, the absorption spectra were recorded utilizing the UV spectrometer. Results: Saliva was detected with $64 \%$ of samples showing a peak at $282 \mathrm{~nm}$. The technique proved to be very specific and sensitive, and it did not deteriorate the sample. Conclusion: UV-spectroscopy is a specific and technique sensitive method that could detect the presence of saliva without deteriorating the quality of the given sample.
\end{abstract}

Keywords: Salivary Alpha-amylase, Spectroscopy

Article chronicle: Date of Submission: 27.03.2019; Date of Acceptance: 04.05.2019; Date of Publication: 24.04.2020

\section{Introduction}

Biological remnants are of the utmost importance in forensic investigations. The presence of this evidence at the crime scene can translate into reliable information to forensic practitioners. ${ }^{1}$ Among the many biological remains found at the crime scene, saliva is usually retained on the skin surface during biting or licking and found in many cases of sexual assault as well as other criminal cases. ${ }^{2}$ It becomes mandatory to detect biological samples including saliva, for further investigation and DNA analysis. Large quantities of salivary amylase enzyme are present in saliva, which aids in the detection of salivary stains. ${ }^{3}$ Detecting dried saliva from human skin could be a major assistance for establishing human identity.
Although it is challenging to collect dried saliva since it is invisible to the naked eye, it can be sampled using a double swab technique. ${ }^{4}$

Ultraviolet (UV) spectroscopy is a technique where radiation-induced electronic transition occurs in a tested material with an ion or molecule of a tested material exhibiting absorption in the UV visible section. This results in alteration in the electronic state of the molecule in the study sample.

In testing for saliva, UV spectroscopy could have the advantages of being noninvasive, highly sensitive, and selective technique through which one can quantify the absorbance of a specified substance at a defined wavelength. A standard UV spectroscope is designed for measuring the absorption of monochromatic light

*Author for correspondence 
by colorless compounds which are near UV trail of the spectrum $(200-380 \mathrm{~nm}) .^{5}$

\section{Aims and objectives}

1. To detect the presence of dried saliva on human skin by UV spectroscope

2. To determine the optimal absorption wavelength of undiluted saliva (whole saliva) and dried saliva from the skin using UV spectroscopy.

\section{Materials and Methodology}

The present study involved 50 participants with predefined inclusion and exclusion criteria. All the participants included were within the age group 20-30 years without any signs of oral mucosal pathology and without any evidence of abnormality related to the functioning of salivary glands as observed on clinical examination. Informed consent was obtained from all the participants, and permission to conduct the study was obtained from the Institutional Ethics committee, where the study was conducted.

The entire study was designed and conducted in three steps:

\section{Step 1: Assessment of maximum absorption wavelength of undiluted saliva}

The saliva was collected with sterilized cotton balls that were kept on the salivary gland duct opening and subsequently were collected in cuvettes excited using UV spectroscope to excitation wavelengths between 200 and $400 \mathrm{~nm}$. The peak absorption wavelength was recorded and used as a standard emission spectrum for the collected dried saliva samples.

\section{Step 2: Ultraviolet spectroscopy of saliva samples (dried) from skin}

Saliva was collected using a double swab technique. ${ }^{4}$ At normal room temperature in the morning, 50 volunteers deposited their saliva on a distinct area marked on their own forearm. Before the process of depositing saliva, the forearm was washed with routine liquid soap, so as to prevent any source of contamination. Further, the forearm was made to air dry for 30-45 min. Subsequently, a cotton swab was dipped in sterile distilled water $(\mathrm{pH} 7)$ for $30 \mathrm{~s}$.
This swab was rubbed on the predetermined marked area twice, first, directly over the cleansed demarked surface and second, after air drying it for $30 \mathrm{~min}$.

The collected sample swab was then mixed in a cuvette containing distilled water ( $\mathrm{pH} 7$ ) for $10 \mathrm{~s}$ and subsequently transferred to a quartz cuvette for recording UV emission spectrum using a Labtronics UV double beam spectrophotometer model number LT2900 (Haryana, India) between excitation wavelengths $200-400 \mathrm{~nm}$ with a dilution of $3.5 \mathrm{ml}$ and a path length of $1 \mathrm{~cm}$.

\section{Step 3: Ultraviolet spectroscopy of deionized water}

Pure distilled water with $\mathrm{pH} 7$ was kept in a quartz cuvette. The UV emission spectrum was documented between excitation wavelengths $200-400 \mathrm{~nm}$ using a spectrometer. All the methods were carried out in accordance with the manufacturer's guidelines.

\section{Results}

\section{Ultraviolet spectroscopy of whole saliva}

The wavelength maximum (absorption spectra) of the whole saliva was recorded at $282 \mathrm{~nm}$ [Figure 1]. This wavelength peak was obtained after subjecting the whole saliva to the spectroscope fixed at the highest absorption wavelength for obtaining absorption outcome for test samples.

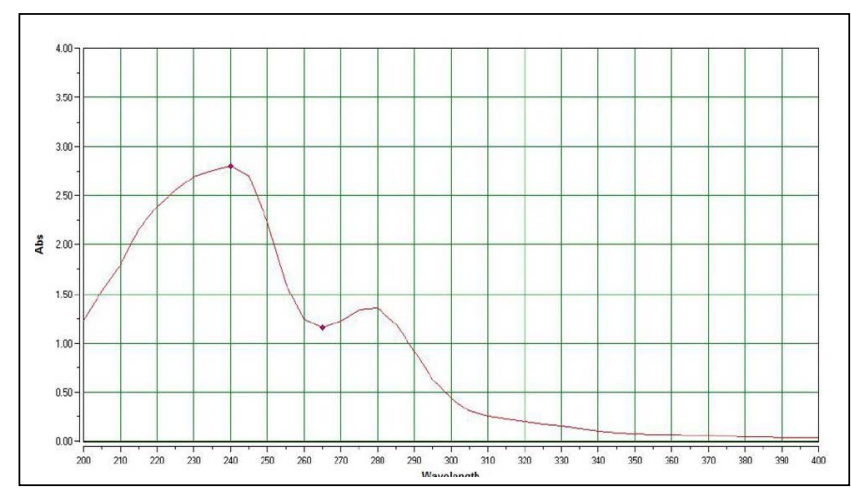

Figure 1: The wavelength of whole saliva samples at 282 $\mathrm{nm}$ using ultraviolet spectroscopy.

\section{Ultraviolet spectroscopy of dried saliva samples from the skin (test samples)}

The absorption wavelength of 50 test samples was identified at the primary peak of 280-282 $\mathrm{nm}$. Other 
peaks were also seen, which could be due to impurities [Figure 2].

\section{Ultraviolet spectroscopy of deionized water}

Deionized water showed no peak [Figure 3].

\section{Discussion}

The bodily fluids can be detected using a screening test, which is also known as a presumptive test. This test can ascertain the likelihood that a substance being examined is a bodily tissue or fluid and is followed by a confirmatory test. The confirmatory test is used to decisively identify specific biological material. ${ }^{6}$ In the present study, UV-spectroscopy is used as a screening test for detecting dried saliva. Although various techniques for detecting dried saliva are available (such as usage of various lights and chemicals), each test has its limitations. Spectroscopy has an advantage due to its efficiency and rapid nature.

On the 50 swab samples taken from dried saliva, an absorption spectrum was taken using UV spectroscopy,

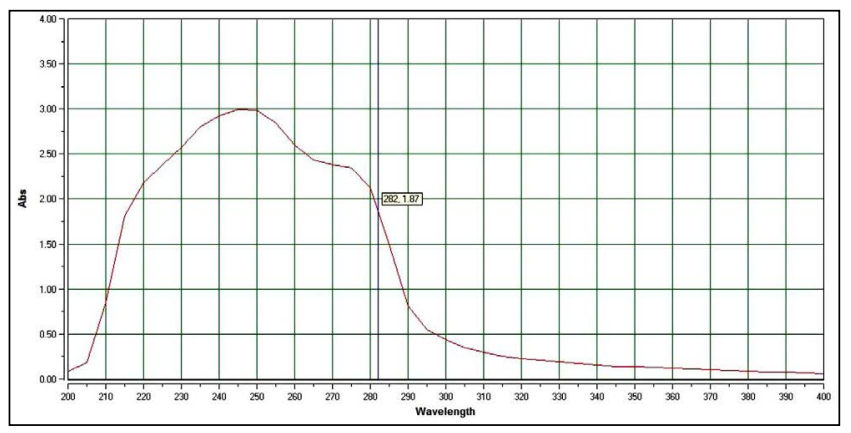

Figure 2: The wavelength of dried saliva samples at 282 $\mathrm{nm}$ from the skin using ultraviolet spectroscopy. Other peaks are because of impurities.

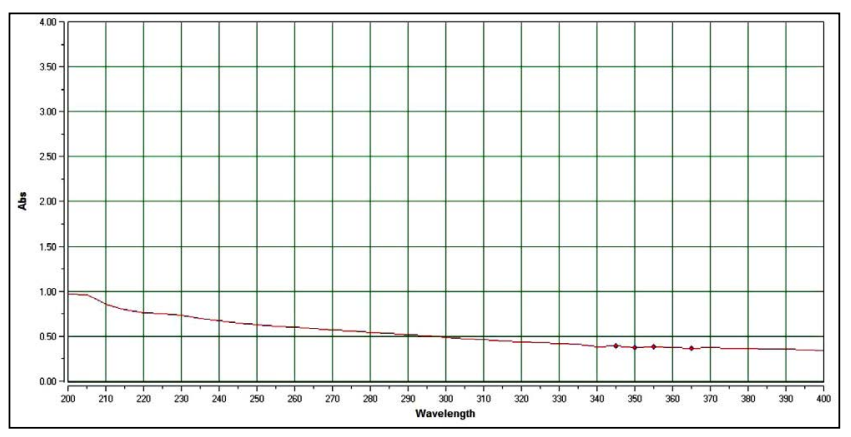

Figure 3: The wavelength of deionized water with no peak using ultraviolet spectroscopy. and had a parallel peak wavelength. ${ }^{8}$ It was also noted that UV intensity peak in saliva was found to fluctuate among the 50 volunteers. These fluctuations may be due to the variation of protein content of saliva in each individual. Other peaks were also found apart from 282 to 285 ranges, which may be due to other impurities present. The mean and the standard deviation were calculated, and it was found that $64 \%$ of the test samples matched the excitation wavelength of positive control (280) [Table 1]. Deionized water showed no peaks. The dried saliva on the skin can also be detected using fluorescent spectroscopy which records the wavelength of aromatic amino acid and tryptophan. This is one of the base amino acids in salivary amylase with an outflow range at $345-355 \mathrm{~nm}$ when energized at a specific wavelength of $282 \mathrm{~nm} .{ }^{7} \mathrm{UV}$-spectroscopy is cost effective, moreover, easily available and equally specific as that of fluorescent spectroscopy. which is based on the absorption principle.

Table 1. The maximum absorption spectra of test samples were characterized by an excitation peak at $280.82 \mathrm{~nm}$ with a range of $280-285 \mathrm{~nm}$

\begin{tabular}{ccccc}
$\begin{array}{c}\text { Mean for } \\
\text { higher } \\
\text { wavelength }\end{array}$ & SD & Highest & Lowest & $\begin{array}{c}\text { Percentage } \\
\text { of samples } \\
\text { matching WL } \\
\text { for saliva }\end{array}$ \\
\hline 280.82 & 1.382 & 285 & 280 & 64 \\
\hline
\end{tabular}

$64 \%$ of the test samples matched the excitation WL of positive control (280). SD: Standard deviation, WL: Wavelength

\section{Conclusion}

UV spectroscopy technique could be used to confirm the presence of saliva to signal further DNA extraction and typing, with the advantage of being quick, sensitive, and noninvasive.

\section{Acknowledgment}

We would like to acknowledge Dr. C. Thamarai Selvan, Asst. Professor, Maulana Azad Institute of Dental Sciences, New Delhi, for helping in standardizing this study, and Mr. Bhuvnesh Kumar Singh Asst. Professor Department of pharmaceutical analysis, College of Pharmacy, Teerthanker Mahaveer University, Moradabad, Uttar Pradesh. 


\section{Financial support and sponsorship}

Nil.

\section{Conflicts of interest}

There are no conflicts of interest.

\section{References}

1. Zapata F, Gregório I, García-Ruiz C. Body fluids and spectroscopic techniques in forensics: A perfect match? J Forensifc Med 2015;1:1000101.

2. Anzai-Kanto E, Hirata MH, Hirata RD, Nunes FD, Melani RF, Oliveira RN. DNA extraction from human saliva deposited on skin and its use in forensic identification procedures. Braz Oral Res 2005;19:216-22.

3. Schenkels LC, Veerman EC, Amerongen AV. Biochemical composition of human saliva in relation to other mucosal fluids. Crit Rev Oral Biol Med 1995;6:161-75.
4. Sweet D, Lorente M, Lorente JA, Valenzuela A, Villanueva E. An improved method to recover saliva from human skin: The double swab technique. J Forensic Sci 1997;42:320-2.

5. Shah RS, Shah RR, Pawar RB, Gayakar PP. UV-visible spectroscopy- A review. Int $J$ Inst Pharm Life Sci 2015;5:490-505.

6. Chatterjee S, Nagi R, Aravinda K, Rakesh N, Jain S, Kaur N, et al. Saliva as a forensic tool. J Dent Probl Solut 2018;5:26-8.

7. Nanda KD, Ranganathan K, Umadevi K, Joshua E. A rapid and noninvasive method to detect dried saliva stains from human skin using fluorescent spectroscopy. J Oral Maxillofac Pathol 2011;15:22-5.

8. Liang T, Roy R. Ultraviolet-visible spectrophotometry (UV-VIS) and SALIgAE ${ }^{\circledR}$ qualitative and semi-quantitative tools for the analysis of salivary amylase. J Forensic Res 2014;5:1.

How to cite this article: Malik SD, Malik U, Sanath AK, Goyal M, Nayak MT, Chowdhry A. Detection of Dried Saliva on Human Skin using an Ultra Violet Spectrometer: A Technical Report. J Forensic Dent Sci 2020;12(1):31-34.

\begin{tabular}{|l|c|}
\hline \multicolumn{2}{|c|}{ Access this article online } \\
\hline \multirow{3}{*}{ Website: } & Quick Response Code \\
\cline { 2 - 2 } www.jfds.org & $\square$ \\
& \\
& \\
&
\end{tabular}

